\title{
Improved detection and Coulomb stress computations for gas-related, shallow seismicity, in the Western Sea of Marmara
}

\author{
Tary Jean-Baptiste ${ }^{1,{ }^{*}}$, Géli Louis ${ }^{2}$, Lomax Anthony ${ }_{4}^{3}$, Batsi Evangelia ${ }^{2}$, Riboulot Vincent ${ }^{2}$, Henry
}

${ }^{1}$ Departamento de Geociencias, Universidad de los Andes, Bogotá, Colombia

2 Institut Français de Recherche pour l'Exploitation de la Mer (IFREMER), Marine Geosciences

Research Unit, BP 70, 29280 Plouzané, France

${ }^{3}$ ALomax Scientific, 320 Chemin des Indes, 06370, Mouans Sartoux, France

${ }^{4}$ Aix Marseille University, CNRS, IRD, INRA, Collège de France, CEREGE, Aix-en-Provence, France

* Corresponding author : Jean-Baptiste Tary, email address : jb.tary@uniandes.edu.co

\begin{abstract}
:
The Sea of Marmara (SoM) is a marine portion of the North Anatolian Fault (NAF) and a portion of this fault that did not break during its 20th century earthquake sequence. The NAF in the SoM is characterized by both significant seismic activity and widespread fluid manifestations. These fluids have both shallow and deep origins in different parts of the SoM and are often associated with the trace of the NAF which seems to act as a conduit. On July 25th, 2011, a 5 strike-slip earthquake occurred at a depth of about $11.5 \mathrm{~km}$, triggering clusters of seismicity mostly located at depths shallower than $5 \mathrm{~km}$, from less than a few minutes up to more than 6 days after the mainshock. To investigate the triggering of these clusters we first employ a match filter algorithm to increase the number of event located and hence better identify potential spatio-temporal patterns. This leads to a 2-fold increase in number of events relocated, coming mostly from the shallow seismic clusters. The newly detected events confirm that most of the aftershocks are shallow, with a large number of events located in the first few km below the SoM seafloor.
\end{abstract}

Pore pressure diffusion from the position of the deep mainshock to the position of the shallow events is incompatible with the short time interval observed between them. We therefore investigate static and dynamic stress triggering processes. The shallow clusters fall into either positive or negative lobes with static stress variations of about $\pm 5 \mathrm{kPa}$. Dynamic stresses may reach values of about $\pm 40 \mathrm{kPa}$ depending on the rise time and the fault orientation considered, but cannot last longer than the perturbations associated with the seismic waves from the mainshock. We then propose a mechanism of fluid pressure increase involving local fluid transfers driven by the transient opening of gas-filled fractures due to earthquake shaking, to explain the triggering of the shallow events of the clusters. 


\section{Highlights}

- A 5 earthquake at depth triggered a shallow cluster of a few hundred events. Newly detected events with the match filter technique confirms the presence of the shallow cluster. Stress transfer computations of static and dynamic stresses are within $\pm 40 \mathrm{kPa}$. Stress transfer cannot explain longlasting effects of a few days during the sequence. We propose a gas-filled fracture model associated with fault reactivation to explain the sequence.

Keywords : shallow seismicity, triggering, stress transfer, North Anatolian Fault, Sea of Marmara 


\section{Introduction}

The Sea of Marmara (SoM) is located South of Istanbul, Turkey, in between the Black and Aegean seas (Figure 1). The SoM comprises 3 deep basins, the narck, Central and Tekirdag basins, associated with the Northern Branch of the North Anatolian Fault (NAF).

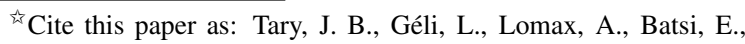
Riboulot, V., Henry, P., 2019. Improved detection and Coulomb stress computations for gas-related, shallow seismicity, in the Western Sea of Marmara. Earth and Planetary Science Letters 513, 113 - 123, doi: 10.1016/j.eps1.2019.02.021.

Email address: jb.tary@uniandes . edu.co (Jean Baptiste Tary)
}

Preprint submitted to Earth and Planetary Earth Letters
The NAF is a continental, dextral strike-slip fault running through the northern part of Turkey. From 1668 to 1766 and from 1939 to 1999, two earthquake sequences ruptured the NAF from East to West [e.g., Stein et al., 1997]. The last sequence in the 20th century reached Izmit and Düzce in 1999 with two earthquakes with moment magnitudes of 7.6 and 7.2, respectively [Barka et al., 2002; Konca et al., 2010]. With the Ganos segment, which ruptured off sequence in 1912 [Aksoy et al., 2009], the SoM Istanbul segment is the only segment of the NAF that did not break during the last earthquake sequence. Land geodesy [Ergintav et al., 2014] and seismicity studies [Schmittbuhl et al., 2016a, 2016b] indicate that part of the NAF in the SoM is not 
currently fully locked, releasing a significant part of the tectonic loading by aseismic creep. However, the distribution of creep cannot be accurately determined with available land geodesy data [Klein et al., 2017] and a seafloor geodesy experiment in Kumburgaz Basin could not detect significant creep [Sakic et al., 2016].

Apart from its significant seismic activity, another important characteristic of the NAF in the SoM is the presence of gas emissions through the seafloor associated with the fault traces [Kuşçu et al., 2005; Zitter et al., 2008; Géli et al., 2008; Tary et al., 2011; Dupré et al., 2015]. Transient gas emissions were also observed after the Izmit earthquake in the narck basin and Izmit Gulf [Kuşçu et al., 2005]. Biogenic as well as thermogenic gases were sampled on the seafloor [Bourry et al., 2009]. Fluids have diverse origins and, at some specific locations, have components that migrated at least several kilometers upward, such as thermogenic hydrocarbons on the Western High and Central High [Bourry et al., 2009], diagenetically imprinted brines seeping through mud volcanoes [Tryon et al., 2010] and CO2rich fluids carrying mantle Helium at the Western escarpment of the Tekirdag basin [Burnard et al., 2012; Ruffine et al., 2019]. Some of the seismicity might be related to fluid migrations at depth or closer to the seafloor [Tary et al., 2011].

In the SoM, the seismic activity along the NAF is characterized by zones of intense activity organized as clusters [Schmittbuhl et al., 2016a; Tary et al., 2011] or delineating asperities [Bohnhoff et al., 2013], and zones with relatively low seismicity such as the IstanbulSiliviri segment extending across the Kumburgaz basin, from the Central High to the Central Basin [Schmittbuhl et al., 2016b]. In 2011, a magnitude 5 earthquake with a dextral strike-slip focal mechanism occurred below the Western High at a depth of about $11.5 \mathrm{~km}$ [Batsi et al., 2018] (Figure 1). Apart from several aftershocks that occurred at roughly the same depth of the mainshock, this relatively unusually strong event for this zone also apparently triggered numerous events at depths shallower than $5 \mathrm{~km}$ (Figure 1). In this study, we develop a match filter algorithm [e.g., Brown et al., 2008] to improve the detection of lower magnitude events in order to better delineate the spatio-temporal distribution of this seismicity, and explore the potential triggering of these events by static stress transfer [e.g., Stein et al., 1997; Tary et al., 2015], dynamic stress transfer [e.g., Freed, 2005], and fault permeability enhancement.

\section{Data and Network}

The seismic network deployed by IFREMER in the SoM in 2011 consists in 10 Ocean Bottom Seismometers (OBS). They were deployed in the Central and Western parts of the SoM, mainly in and around the Tekirdag and Central basins as well as on the Western High (Figure 1). This zone is targeted due to its significant seismic activity [Tary et al., 2011; Schmittbuhl et al., 2016b; Batsi et al., 2018] and to its intense fluid manifestations including: i) the expulsion of gas bubbles in the water column [Géli et al., 2008; Dupré et al., $2015]$; ii) the presence of gas and gas hydrates within the superficial sediments [e.g., Thomas et al., 2012]) along with the presence of mud accumulation and expulsion identified on the high-resolution bathymetry and seismic profiles [Grall et al., 2013] (Figure 2).

The autonomous OBS acquired continuous data from April 15, 2011 to July 31, 2011. Unfortunately, OBS-2 that was located directly on top of the mainshock and triggered seismicity stopped working on July 01, 2011. Four permanent seafloor observatories operated by the KOERI complement the OBS network. Each OBS has a 3-C short-period geophone (Geospace GS-11D with 4.5 Hz natural frequency) and hydrophone which were sampled at $125 \mathrm{~Hz}$, while the permanent seafloor observatories contain a broad-band seismometer (Guralp CMG-3T) and a hydrophone sampled at a frequency of $100 \mathrm{~Hz}$.

\section{Methods}

\subsection{Detection algorithm and relocation procedure}

Starting with the continuous data of the 10 OBS and the 4 seafloor observatories, we band-pass these data in the frequency band containing the greatest earthquake energy $(15-25 \mathrm{~Hz})$. We then use a match-filter approach [e.g., Brown et al., 2008] to detect small earthquakes within the continuous data. This approach relies on the detection of events with very similar waveforms to known parent events meaning that instrument, path and source (radiation pattern) effects are very similar between events. Typically, this approach detects a larger number of events than classical detection schemes such as energy methods using the ratio of short term average to long term average signal amplitude. The basic concept is to use the cross-correlation of parent events, which are template events generally of higher magnitudes, with the continuous 3-C data streams of the seismic network. The detection threshold in our case is based on the median absolute deviation (MAD) of the 
a) Before child-events relocation
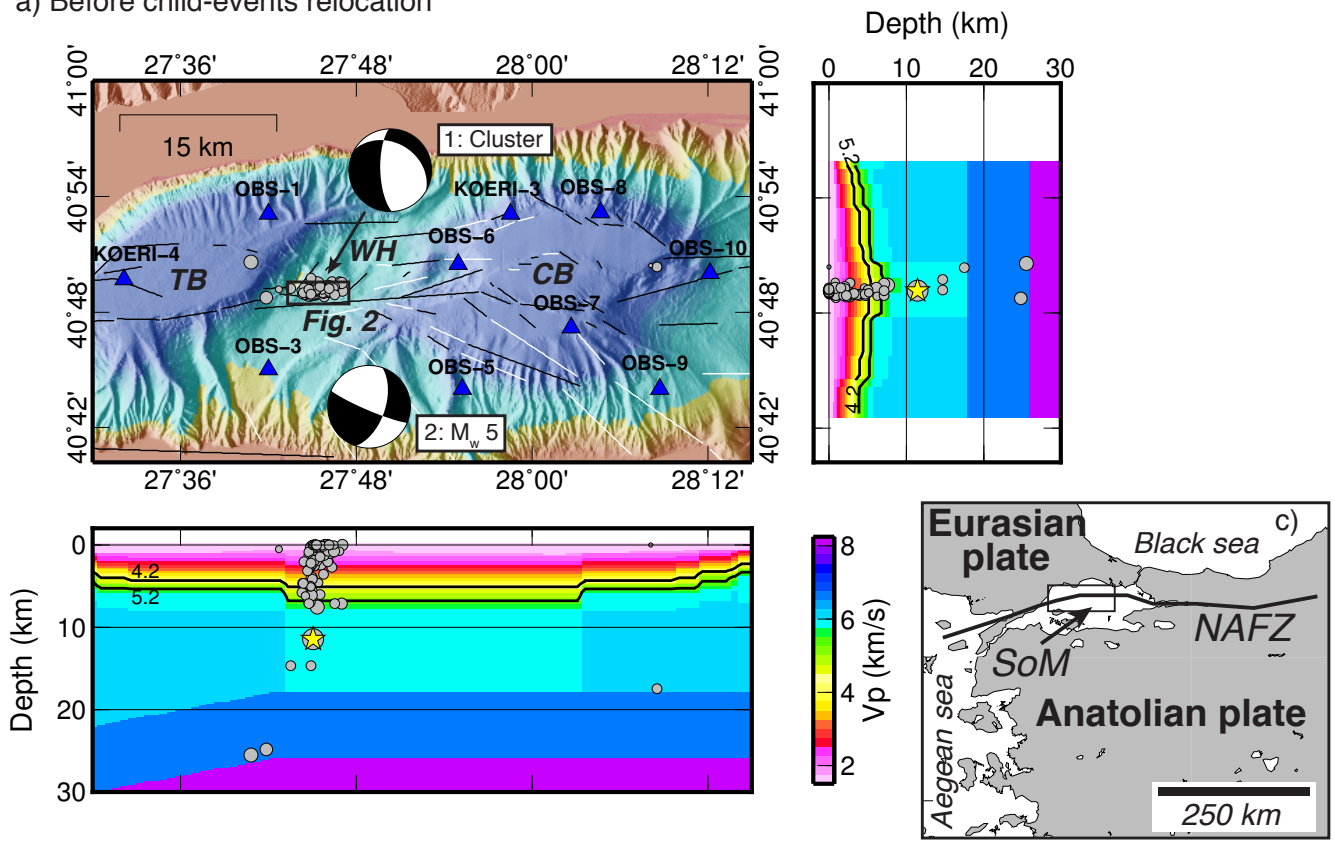

b) After child-events relocation

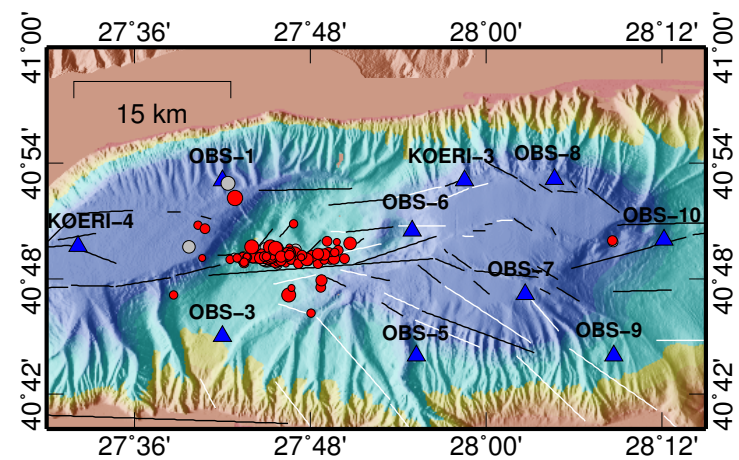

Depth $(\mathrm{km})$
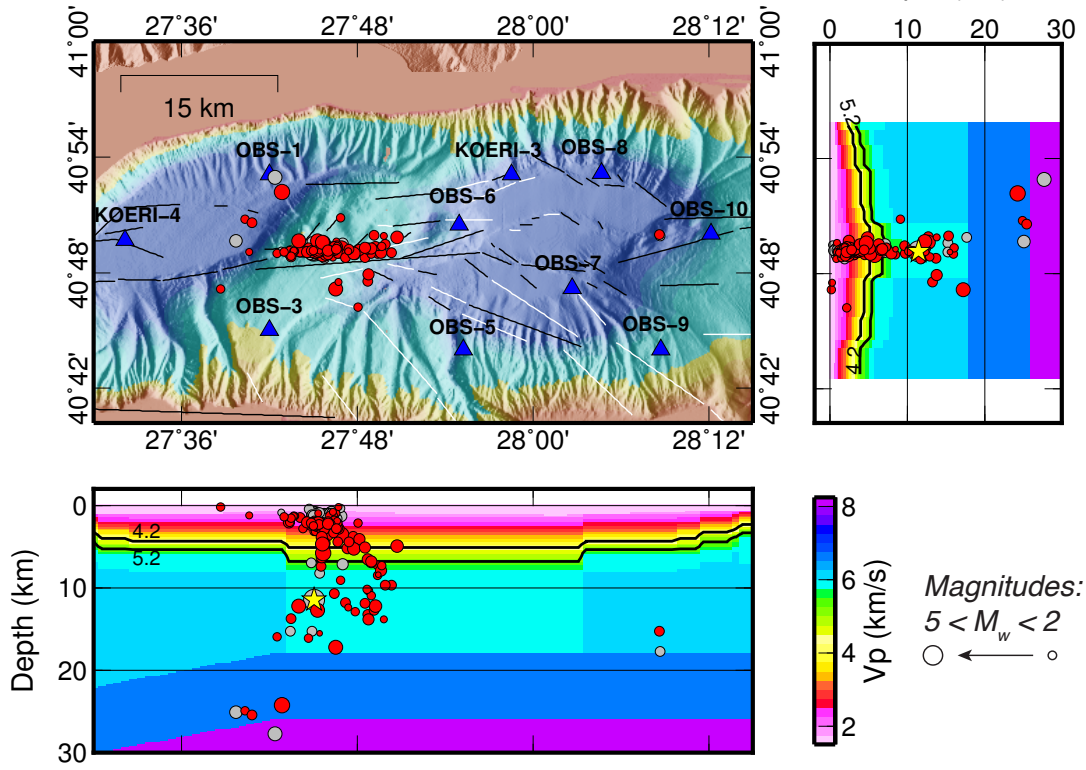

Figure 1: Earthquake relocation before (a) and after (b) child-event relocation following the $\mathrm{M}_{w} 5$ mainshock that occurred on July 25, 2011, at 17:57:21 UTC. The map positions in a) and b) are shown in the map in c). White and black lines correspond to active and presumably inactive faults, respectively (Sengör et al., 2014). Two cross-sections showing the P-wave velocity model of Géli et al., 2018 are shown on the sides of the map. OBSs and seafloor observatories from the KOERI are indicated by the blue triangles. Parent and child-events correspond to the gray and red dots, respectively (symbol sizes scale with moment magnitudes). The mainshock location is indicated by the yellow star. Focal mechanisms of Batsi et al., 2018, for the superficial events (1) and the mainshock (2) are also shown. The position of Figure 2 is indicated by the black square in a). Abbreviations: TB: Tekirdag Basin; WH: Western High; CB: Central Basin. 

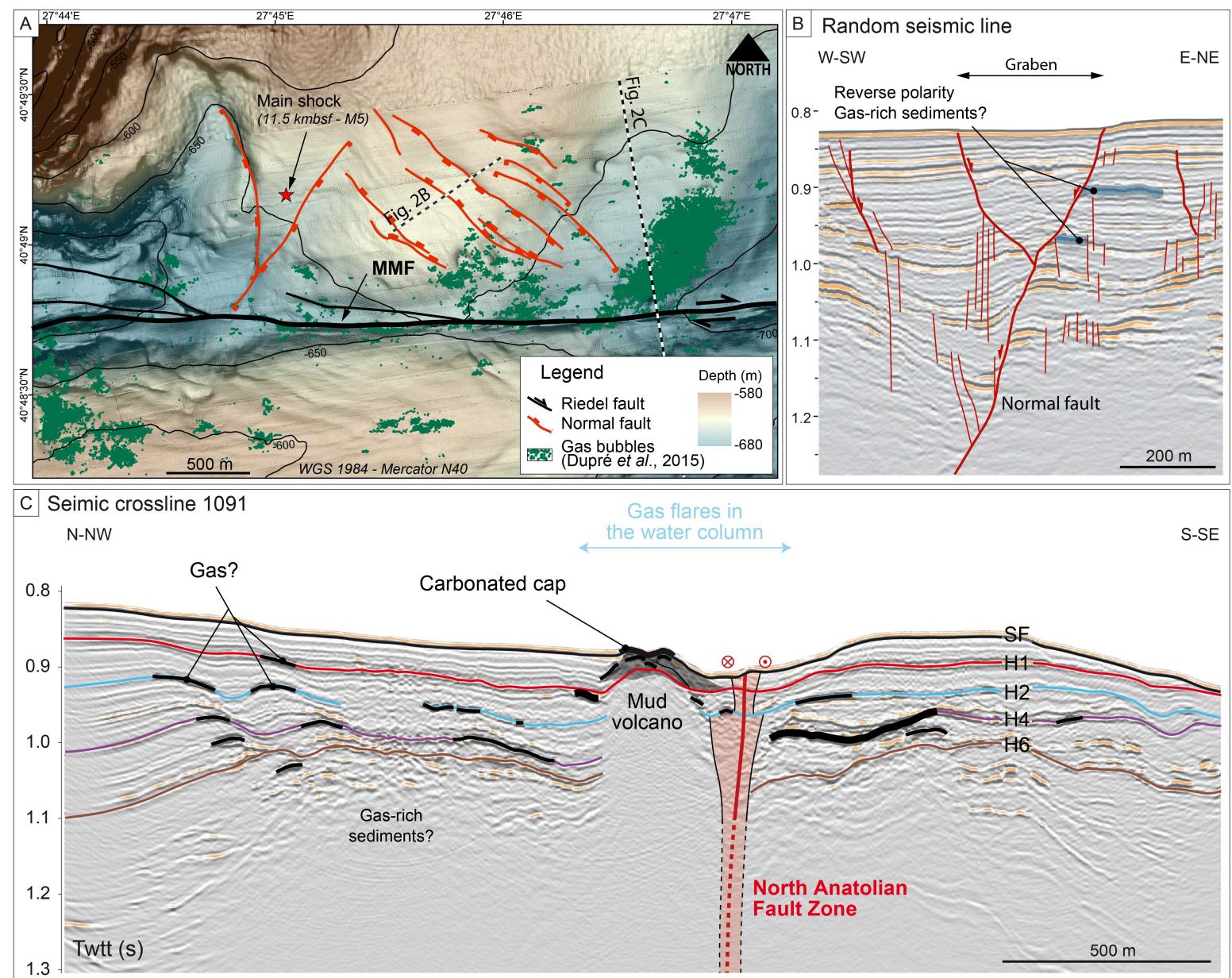

Figure 2: (a) High-resolution bathymetric map of the Western High centered on the NAF. The Main Marmara Fault (MMF) fault system (black lines), faults identified on the high-resolution seismic profiles (red lines), and gas bubbles (green dots) in the water column [Dupré et al., 2015] are also indicated. Two interpreted high-resolution seismic profiles are indicated by the black dashed lines in a), one passing over some normal faults on the northern flank of the Western High (b), and the other passing over a mud volcano and the NAF (c). The seismic profile in c) is reproduced from Géli et al., 2018 (supplementary material, appendix 5). Abbreviations: H1-H6: horizons; SF: sea-floor; Twtt: two-way travel-time. 
trace after cross-correlation and summation over all stations [Brown et al., 2008]. The cross-correlation is carried out solely for stations with time picks for the parent event. This could be complemented by additional picks using ray-tracing and an appropriate velocity model but we found that the calculated travel-times using the available 1-D velocity models [Tary et al., 2011; Géli et al., 2018] come with significant errors that might then prevent the phase identification for the newly detected events.

The data streams are first normalized using the average trace envelope before performing the crosscorrelations. Cross-correlations are done independently for $\mathrm{P}$-waves and $\mathrm{S}$-waves using $1 \mathrm{~s}$ and $1.5 \mathrm{~s}$ windows around $\mathrm{P}$ - and $\mathrm{S}$-waves, respectively. The move-out of the parent event is then taken into account before summing all cross-correlation data, and a detection is identified when a conservative MAD threshold of 10 is exceeded. The newly detected events are then extracted $( \pm 10 \mathrm{~s}$ around MAD maxima) and the events with at least 3 phases with cross-correlation coefficients greater than 0.65 are retained. The cross-correlation coefficients are also saved to be used as weights during the relocation procedure. Since some of the parent events are also highly similar, in some cases other parent events will be detected or the same child-event will be detected more than once using different parent events. We remove these duplicates by searching over all detected events and allowing for only 1 event in $\pm 10 \mathrm{~s}$, retaining the pair parent-child events with the highest crosscorrelation coefficients. We finally estimate differential times with subsample precision using quadratic interpolation around the cross-correlation picks.

The parent events are first located using the NonLinLoc software which is using a non-linear, grid-search algorithm [Lomax et al., 2009], with a 3-D velocity model for the SoM [Bayrackci et al., 2013; Géli et al., 2018]. The parent events are then relocated using the doubledifference method with manual picks only [De Landro et al., 2015]. See Batsi et al., 2018 for more details on these locations. To relocate all child-events together with all parent events, the child-events are initially located at the position of their respective parent event and both manual and cross-correlation derived differential times are used together with the double-difference method.

\subsection{Static and dynamic stress transfer calculations}

Stress perturbations and triggering due to an earthquake can be caused by static stress changes due to the slip on the fault close to the earthquake (i.e., in the near-field), or caused by dynamic stress changes due to seismic waves far away from the earthquake (i.e., in the far-field). Static and dynamic stress variations may both cause persistent pore pressure variations [Roeloffs, 1998] and changes in fluid discharge rates at the Earth surface through various processes including strain, liquefaction/consolidation, and enhancement of fracture permeability. Dynamic stress variations are most likely involved in the triggering of aftershocks, remote seismicity, and fluid-related processes such as mud volcano eruptions and changes in geyser frequency [Freed, 2005; Manga and Wang, 2007]. Perturbations in static stress are usually based on the change in Coulomb failure stress $\Delta \sigma_{c}$ given by [Cocco and Rice, 2002]

$$
\Delta \sigma_{c}=\Delta \tau+\mu\left(\Delta \sigma_{n}+\Delta p\right)
$$

where $\Delta \tau$ and $\Delta \sigma_{n}$ are the changes in shear and normal stresses (positive unclamping) on a given fault plane in the slip direction, respectively, $\mu$ the friction coefficient and $\Delta p$ is the change in pore pressure. For an isotropic, poroelastic medium, the change in pore pressure in the undrained limit is given by [Rice and Cleary, 1976]

$$
\Delta p=-B \frac{\Delta \sigma_{k k}}{3}
$$

with B the Skempton coefficient and $\Delta \sigma_{k k} / 3$ the mean volumetric stress change. In the following, static stress changes in terms of Coulomb, normal and shear stresses, calculated in a homogeneous, elastic halfspace, and on a predefined fault plane are determined using a modified version of Coulomb 3.3 [Lin and Stein, 2004; Toda et al., 2005] incorporating pore pressure changes [Tary et al., 2015]. We estimate the Youngs modulus and Poisson ratio from the P-wave velocity of the model of Géli et al., 2018, at the level of the clusters $(\mathrm{Vp} \sim 3000 \mathrm{~m} / \mathrm{s})$, a $\mathrm{Vp} / \mathrm{Vs}$ ratio of 1.79 determined by Becel, 2006, for the SoM. A P-wave velocity of 3000 $\mathrm{m} / \mathrm{s}$ typically correlates with a S-wave velocity of 1400 $\mathrm{m} / \mathrm{s}$ for clay-rich siliciclastic sediments [Castagna et al., 1985], with a porosity $\phi$ of $20-25 \%$ [Ericksson and Jarrard, 1998], and a density of $2300 \mathrm{~kg} / \mathrm{m}^{3}$. We then use a Youngs modulus of $16.5 \mathrm{GPa}$, a Poisson ratio of 0.27 , and a static coefficient of friction, $\mu$, of 0.25 for clayrich fault zones [Remitti et al., 2015].

Dynamic stress changes for the mainshock are determined by first calculating the displacements radiated by the 6 independent components of the moment tensor, and then calculating the corresponding displacements at other locations using the reflectivity method of Kenneth and Kerry, 1979, together with the discrete wavenumber method of Bouchon, 1981. The dynamic stress calculation is carried out by the code AXITRA of Cotton 
and Coutant, 1997. The dynamic stresses can be calculated for a layered medium, different source fault geometries using sub-faults or fault patches, and for a predefined number of sources and receivers. A point source with the source characteristics of the mainshock (i.e., in terms of seismic moment and focal mechanism) is setup at $11.5 \mathrm{~km}$ depth, and the dynamic stress changes are calculated at the mean depth of the cluster (i.e., 1.5 $\mathrm{km})$ using a 1D velocity model extracted from the 3D model of Géli et al., 2018 at the position of the clusters. The source time function employed is a ramp with different rise times. The rise time $\tau_{R}$ is determined using [Madariaga, 1976]

$$
\tau_{R}=\frac{G S}{\beta \Delta \sigma},
$$

where $G$ is the shear modulus, $S$ the mean slip, $\beta$ the shear wave velocity, and $\Delta \sigma$ the stress drop. We use the properties at the level of the mainshock with a shear modulus $G$ of $30 \mathrm{GPa}$, a shear wave velocity $\beta$ of 3000 $\mathrm{m} / \mathrm{s}$, a uniform mean slip of $0.15 \mathrm{~m}$ obtained from scaling relationships for a magnitude 5 earthquake [Wells and Coppersmith, 1994], and stress drops $\Delta \sigma$ between 1 and $10 \mathrm{MPa}$, and obtain rise times between 0.15 and 1.5 s. In the following, we test 3 values of rise times $(0.3$, 0.5 and $1 \mathrm{~s}$.) and the dynamic stress changes are then transformed into changes in shear, normal and Coulomb stresses on a given fault plane (eq. 1).

\subsection{Fluid-filled material parameters and Skempton co- efficient}

In order to examine a possible coupling between fluid and seismicity, we first evaluate the conditions and properties of the fluid and the formation where most of the aftershocks are clustered. A depth below sea-surface of about $3 \mathrm{~km}$ (and, hence below seafloor of about 2.4 $\mathrm{km}$ ) may be considered typical (see, for instance, Figure 1). At this depth, water hydrostatic pressure is 30 $\mathrm{MPa}$ and temperature is estimated to be $60^{\circ} \mathrm{C}\left( \pm 20^{\circ} \mathrm{C}\right)$ [Géli et al., 2018]. We hereafter consider the properties of the methane gas because it is the one most commonly observed in the Sea of Marmara. At $30 \mathrm{MPa}$ and $60^{\circ} \mathrm{C}$, methane density is about $150 \mathrm{~kg} \cdot \mathrm{m}^{-3}$ and its viscosity is about $2.10^{-6}$ Pa.s [Nunn and Meulbroek, 2002]. Water density and viscosity is approximated as $1000 \mathrm{~kg} . \mathrm{m}^{-3}$ and $10^{-3}$ Pa.s, respectively. Undrained moduli are calculated from seismic wave velocities and density (bulk modulus $K_{u}$ of $15 \mathrm{GPa}$ and shear modulus of $4.6 \mathrm{GPa}$ ), and a drained bulk modulus $K$ of $8 \mathrm{GPa}$ is inferred using Gassman's equation and assuming a water bulk modulus $K_{w}$ of $2.25 \mathrm{GPa}$, a solid phase bulk modulus $K_{s}$ of

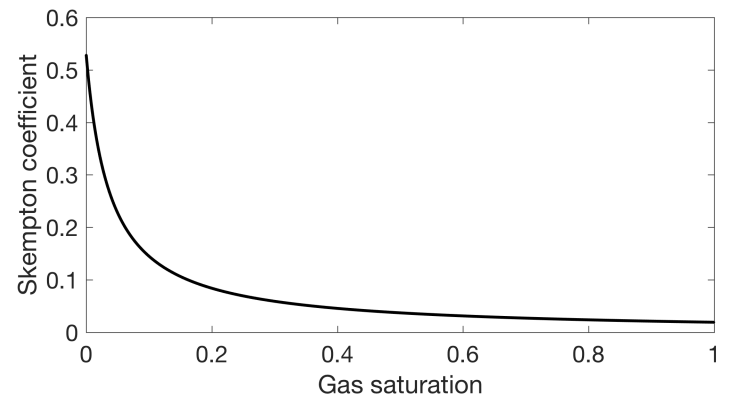

Figure 3: Skempton coefficient B as a function of gas saturation. See text for computation parameters.

$50 \mathrm{GPa}$, a shear modulus of $30 \mathrm{GPa}$ and solid density of $2670 \mathrm{~kg} \cdot \mathrm{m}^{-3}$. We here consider that the undrained conditions hypothesis is valid at short time scales corresponding to the earthquake duration under consideration (i.e., $30 \mathrm{~s}$ ). Under these conditions, we may use the Skempton coefficient B to compute changes in pore pressure. The Skempton coefficient varies from 0 to 1 , water saturated rocks usually having values between 0.5 and 0.9 and tending toward zero as fluid compressibility increases to large values, which can be the case if the pores are filled with gas. For a poroelastic, linear, isotropic material, the Skempton coefficient is given by [Makhnenko and Labuz, 2013]

$$
B=\frac{\alpha}{\alpha+\phi K\left(C_{f}-\frac{1}{K_{s}}\right)},
$$

where $\alpha$ is the Biot-Willis coefficient expressed as $\alpha=1-K / K_{s}$, and $C_{f}$ is the fluid compressibility given by

$$
C_{f}=\frac{S_{g}}{K_{g}}+\frac{\left(1-S_{g}\right)}{K_{w}}
$$

with $S_{g}$ the gas saturation, and $K_{g}$ the methane approximate bulk modulus for adiabatic compression (40 $\mathrm{MPa}$ ). Using this procedure, we calculate the Skempton coefficient $B$ varying the gas saturation from 0 to 1 (Figure 3 ). For the stress transfer calculations, we use 2 values of the Skempton coefficient B, one corresponding to a high gas saturation $(B=0.1)$ and one corresponding to a gas-free medium $(B=0.6)$. 


\section{Results}

\subsection{Improved detection}

Using 85 events previously located as parent events coming from the shallow clusters and the deeper seismicity [Batsi et al., 2018], about 1266 events are detected, of those, 136 are selected (number of phases 3 with cross-correlation coefficients $>0.65$ ), and 114 child events are finally relocated together with 84 parent events (Figures 1 and 4). The match-filter approach leads then to a $\sim 2$-fold increase in relocated seismicity. The number of child-events per parent event ranges from 0 to 9 , the mainshock not having any selected child-events. The number and magnitude of new relocated events are mainly limited by the small number of stations available, as this prevents obtaining a sufficient number of high cross-correlation coefficients. The relocated child-events have magnitudes ranging from 1.5 to 3.7, with the events belonging to the superficial cluster (depths $5 \mathrm{~km}$ ) having magnitudes between 1.6 and 3.6 and the deeper events (depths $>5 \mathrm{~km}$ ) having magnitudes between 1.5 and 3.7. Most events are recorded by the 5 nearest OBSs leading to relatively similar azimuthal gaps ranging between 80 and $145^{\circ}$ and similar distances to the nearest stations between 5 and $10 \mathrm{~km}$. The relocation errors, both horizontal and vertical, are mainly between $0.1 \mathrm{~km}$ and $1.5 \mathrm{~km}$ (Figure 5c). Deeper events (depths $>5 \mathrm{~km}$ ) have slightly higher vertical relocation errors between 0.34 and $2 \mathrm{~km}$.

The child events are mainly located within the shallow clusters at depths of less than $5 \mathrm{~km}$. None of these events of these shallow clusters occurred before the mainshock at depth but rather just after the mainshock, starting less than 3 minutes after it for some detected but not relocated events, and lasting for approximately 6 days (Figure 5b). We also observe an exponential decrease in the number of events with time after the mainshock. The newly detected events confirm the presence of an important part of the microseismicity in the shallow part of the sedimentary pile, as found by Batsi et al., 2018. This also includes some events occurring within the upper sedimentary layers (depths $<1$ $\mathrm{km})$. The events from the shallow clusters have a significantly different move-out from the mainshock located at depth (Figure 5a), usually with longer propagation times for the shallow events due to their longer propagation paths within the shallower, low-velocity layers.

Taking into account that many smaller events might not be detected using our procedure, the triggering of the shallower seismicity by the mainshock appears quasi-instantaneous. Considering an isotropic poroelastic medium, the diffusion time of pore pressure can be estimated using $t \sim L^{2} / H_{D}$, with $L$ the diffusion length in the medium and $H_{D}$ the hydraulic diffusivity [Manga and Wang, 2007]. With the triggered clusters located 10 - $15 \mathrm{~km}$ away from the mainshock, and the first detected aftershocks occurring less than 3 min after the mainshock, this would lead to large, unrealistic values of hydraulic diffusivities. Hence, for commonly used hydraulic and poroelastic parameters, this rules out a potential triggering of these events by pore fluid diffusion from deeper levels, a process whose propagation is quantified by the supposedly finite hydraulic diffusivity of the medium [Manga and Wang, 2007]. This assumes that the fluid source originates where the mainshock occurred. This might not be the case and, while the first events might not have been triggered by pore pressure diffusion, this does not rule out this mechanism for later events in the sequence. No migration pattern associated with pore pressure diffusion or nucleation phases of the mainshock are observed either. On the other hand, static stress and dynamic stress effects are quasi-instantaneous (a distance of $\sim 10 \mathrm{~km}$ at seismic velocities of $2-6 \mathrm{~km} / \mathrm{s}$ leads to time lags of $1.7-5 \mathrm{~s}$ ).

\subsection{Stress transfer}

For static stress changes, the events are located within zones of increase or decrease in normal stress and Coulomb failure stress depending on the fault orientation (Figure 6). Fault orientations considered are those corresponding to the composite focal mechanism of superficial events from Batsi et al., 2018 with a strike of 300 , a dip of 34 , and a rake of -143 (i.e., [300, 34, 143]), and faults observed on high-resolution seismic profiles likely associated with some of the shallow seismicity [Batsi et al., 2018] (Figure 2) with orientations $[130,55,-90],[170,65,-90]$ and $[30,55,0]$. Only faults with orientations [300, 34, -143] have an increase in Coulomb stress and positive normal stress (unclamping). These stress changes range approximately from 1 to $5 \mathrm{kPa}$ (Figure 6). The other 2 normal fault orientations $([130,55,-90]$ and $[170,65,-90])$ are associated with smaller positive Coulomb stress changes (maximum $\sim 1.5 \mathrm{kPa}$ ) and with either very small or negative normal stress changes $(\sim-3$ to $1 \mathrm{kPa})$. The leftlateral fault with orientation $[30,55,0]$ is located in positive lobes of Coulomb stress changes $(\sim 5 \mathrm{kPa})$ and in negative lobes of normal stress changes ( 0 to $-3 \mathrm{kPa}$ ). The corresponding changes in pore pressure $\mathrm{p}$ calculated from the mean stress changes and equation 2 are very small and range from -0.1 to $0.25 \mathrm{kPa}$ for a Skempton coefficient $\mathrm{B}$ of 0.1 , and from -0.1 to $1.3 \mathrm{kPa}$ for a Skempton coefficient B of 0.6. 


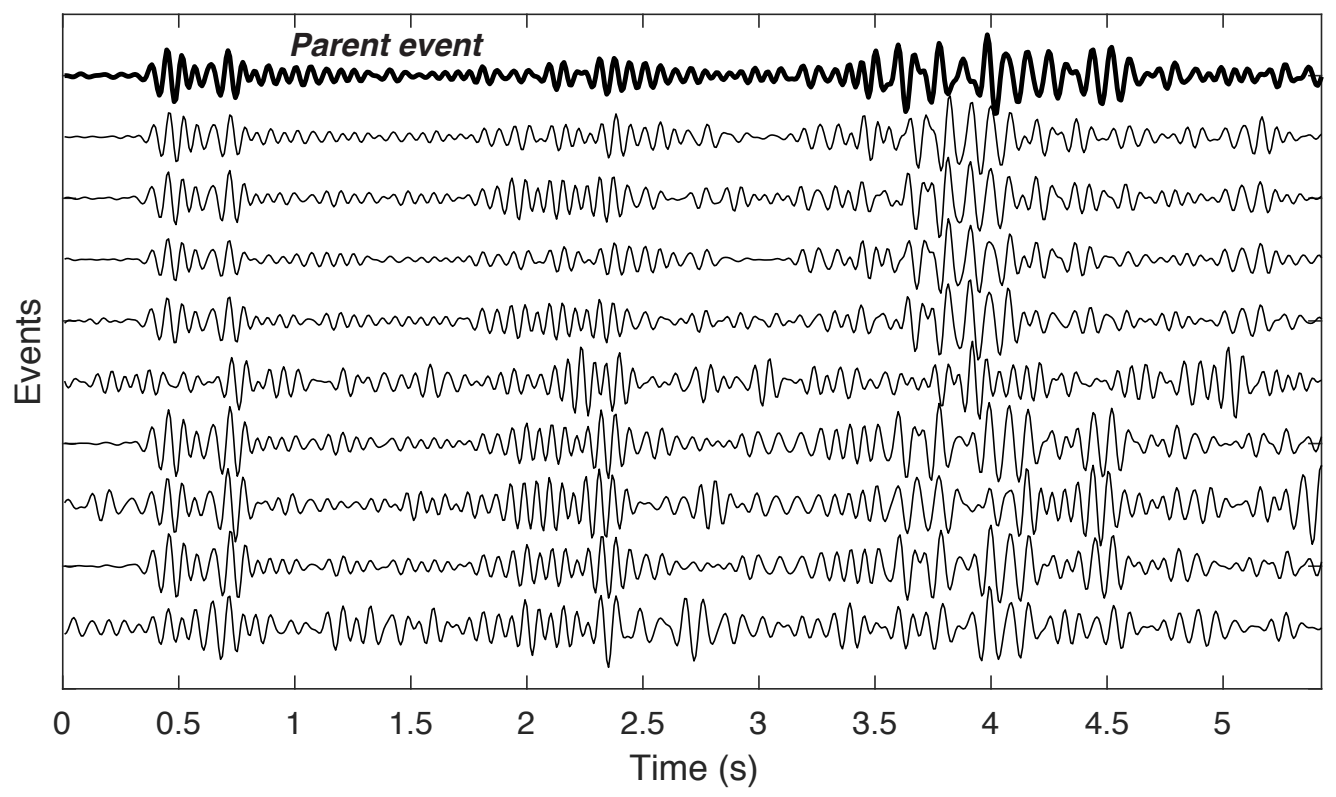

Figure 4: Example of a parent event (thick black line) that occurred on July 25th, 2011, at 18:15:43 UTC with its 8 child-events recorded by OBS-01 (vertical component). The waveforms are filtered between 10 and $20 \mathrm{~Hz}$.

For the dynamic stresses, the maximum stress perturbations correspond to a rise time of $0.3 \mathrm{~s}$ and are within $\pm 40 \mathrm{kPa}$ (Figure 7), which is close to 5-10 times the maximum static stress changes. Faults oriented [300, $34,-143]$ and $[130,55,-90]$ show larger values of dynamic stress changes (within $\pm 40 \mathrm{kPa}$ ) than faults with orientations $[170,65,-90]$ and $[30,55,0]$ with dynamic stress changes within $\pm 20 \mathrm{kPa}$. For faults with orientations [130, 55, -90] and [30, 55, 0], corresponding pore pressure changes $\Delta p$ calculated using equation 2 are about $\pm 5 \mathrm{kPa}$ for a Skempton coefficient B of 0.1 and up to $\pm 15 \mathrm{kPa}$ for a Skempton coefficient $B$ of 0.6. Pore pressures changes from dynamic stresses for the other 2 fault orientations are much smaller, within \pm 5 $\mathrm{kPa}$. Computed dynamic stresses are, for all faults considered, multiple times larger than static stresses. In addition, the effect of dynamic stresses also increases over time through cyclic loading of the medium. In the present case, the signal duration of the mainshock lasted for about 20-30 s at the location of the shallow seismicity (depth $<5 \mathrm{~km}$ ), which means that Coulomb stress changes directly related to dynamic stress perturbations lasted for about $30 \mathrm{~s}$. Because these Coulomb stress changes are not producing long-lasting effects directly, we propose hereafter a gas-filled fracture model involving the stress changes as a trigger for increases in fault permeability leading to fluid migration and fault insta- bility.

\subsection{Gas-filled fracture model}

Enhancement of fault permeability during and/or after an earthquake will likely result in upward fluid migration and pore pressure redistribution if the fluid pressure gradient in the fluid differs from that at hydrostatic equilibrium. This may for instance occur with water as the migrating fluid if the pore pressure gradient is above hydrostatic, or as a result of buoyancy effects if a phase of lower density fluid (for instance, gas) is present. Assuming that a gas phase is subject to a pressure gradient imposed by a continuous water phase, and that the water pressure gradient is hydrostatic, the opening and/or formation of fractures will result in a transient increase of the upward gas flux. According to Poiseuille law, the average velocity of fluid ascent may be related to the hydraulic opening of fractures as

$$
V_{a}=\frac{b^{2}}{12 \eta}\left(\frac{d P}{d z}-\rho g\right),
$$

where $\eta$ is the fluid viscosity, $\rho$ the fluid density, $b$ the hydraulic opening, $P$ the pressure, $z$ the depth, and $g$ the gravity acceleration. Considering in situ conditions at $3 \mathrm{~km}$ depth where most of the aftershocks occurred, the ascending velocity for methane gas subject to water hydrostatic ambient pressure would be (with 

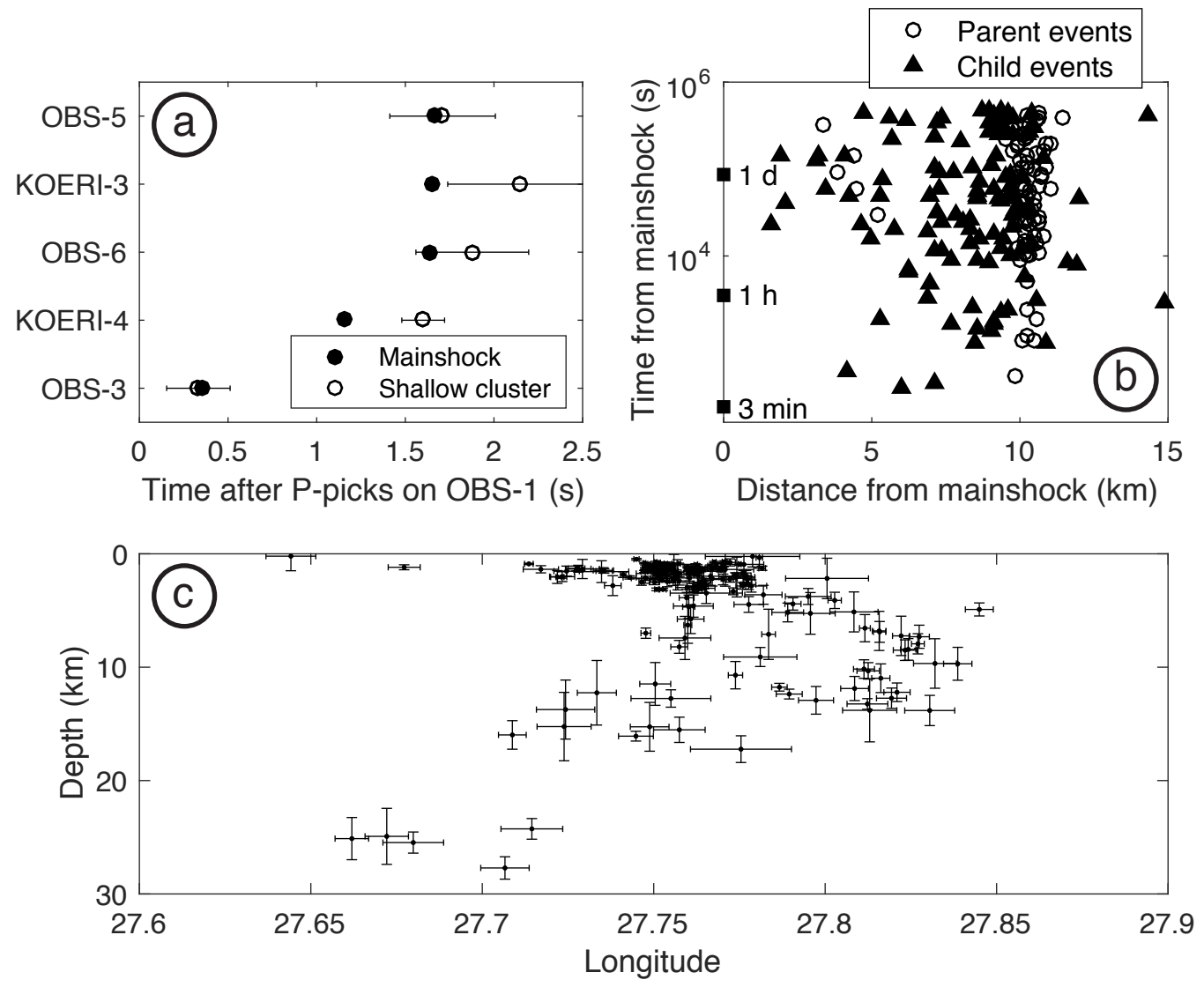

Figure 5: a) Move-out of P-waves of the mainshock (black dots) compared with the average move-out of the parent events part of the shallow cluster (circles). The error bars represent 1 standard deviation from the average. The stations are ordered from the lowest to largest arrival times for the mainshock. b) Occurrence times of parent (circles) and relocated child-events (triangles) from the time of the mainshock as a function of the distance from the mainshock. c) East-west cross-section showing the location of the child-events after relocation with error-bars. 


\section{A) Coulomb stress changes}
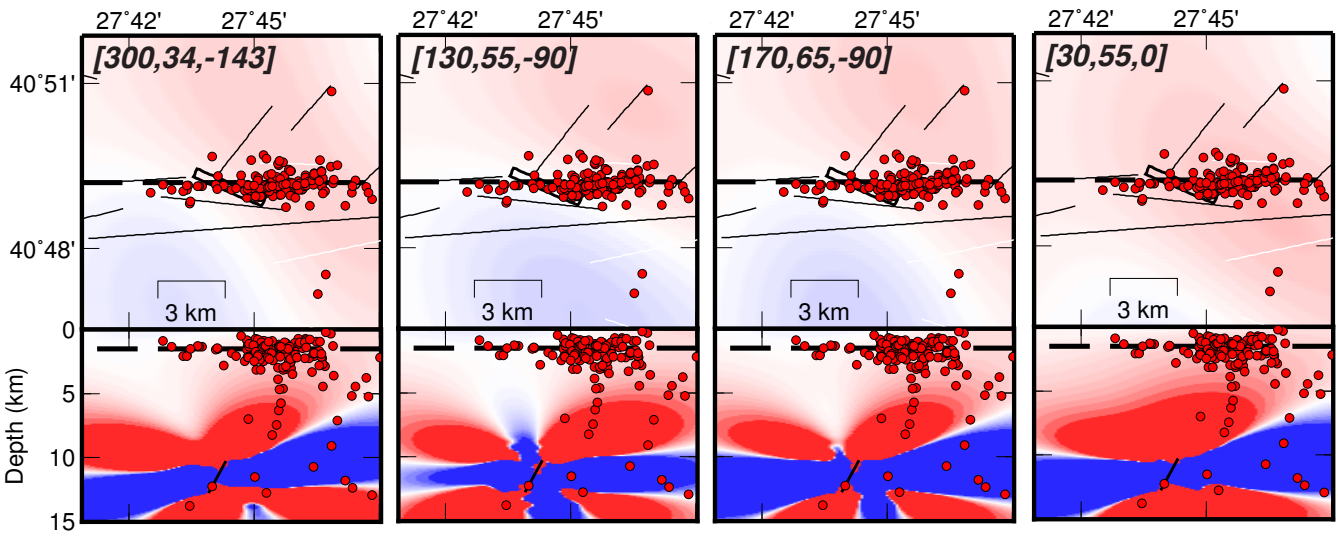

\section{B) Normal stress changes}
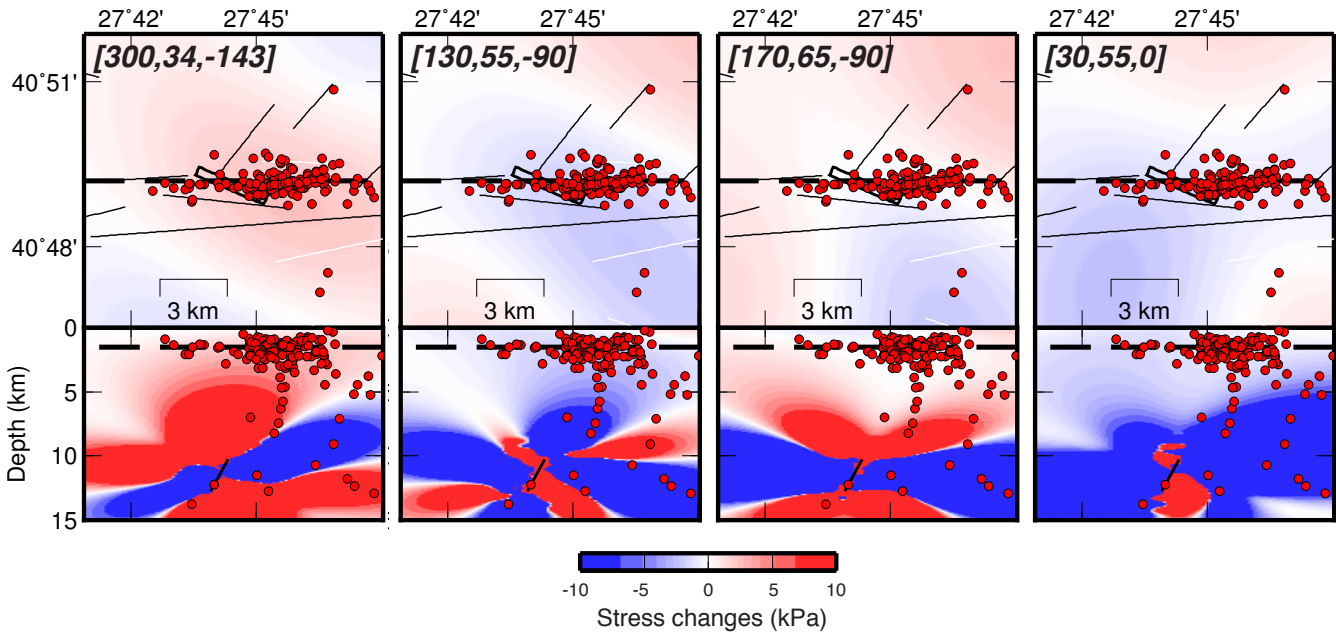

Figure 6: Coulomb stress (a) and normal stress (b) changes calculated on faults with different orientations [strike, dip, rake] ([300, 34, -143] corresponds to the composite focal mechanism of the superficial events of Batsi et al., 2018; the other orientations are faults observed on the high-resolution seismic profiles). Dashed black lines on maps corresponds to the cross-section positions, while dashed black lines on cross-sections correspond to the depth of the stress changes shown on the maps $(1.5 \mathrm{~km})$. For the Coulomb stress changes, these computations are corresponding to a Skempton coefficient B of 0.1, using a Skempton coefficient B of 0.6 does not change significantly the results. The black rectangle on the map and the solid black line on the cross-section correspond to the fault plane of the mainshock. 

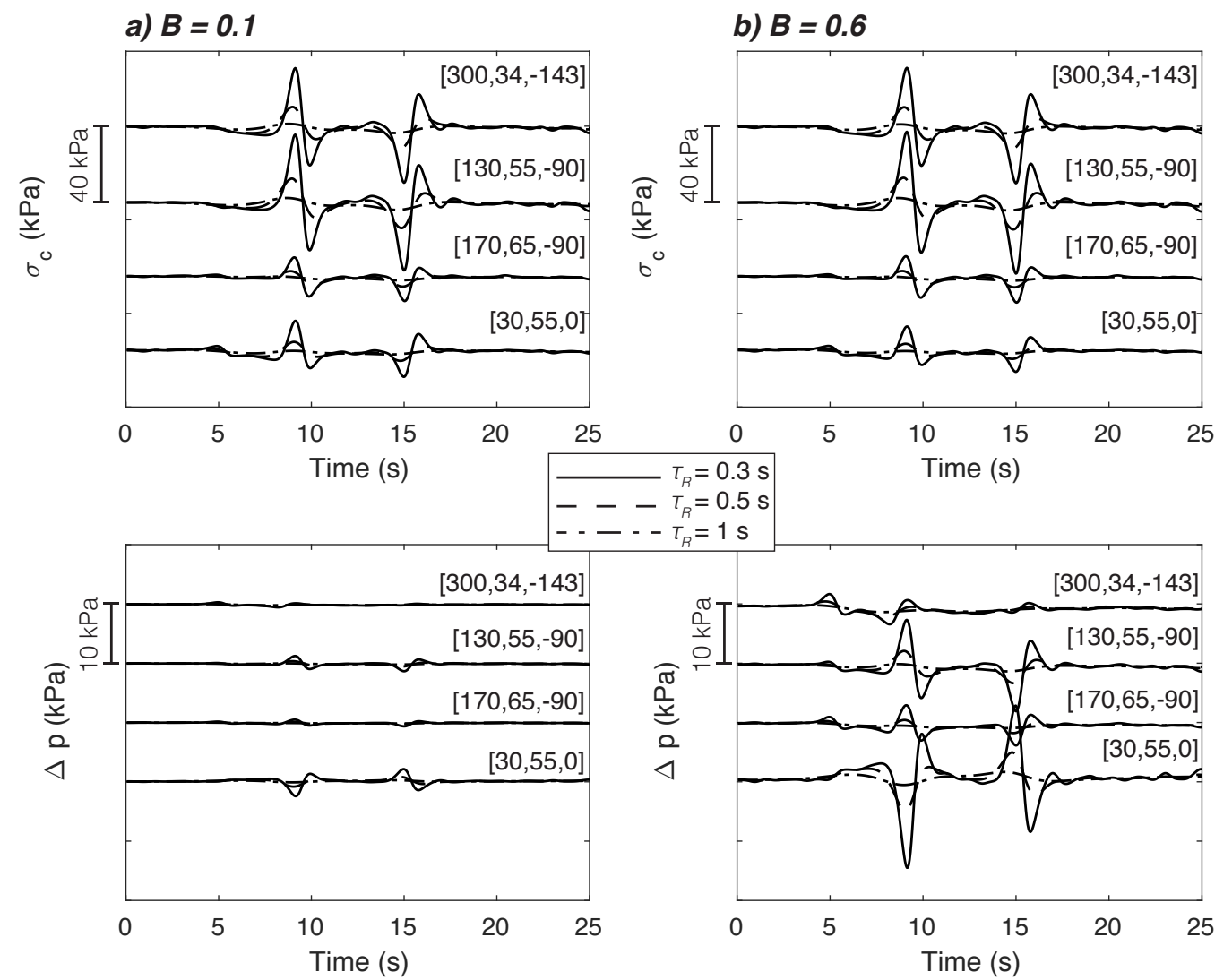

Figure 7: Dynamic stresses calculation on faults with different orientations [strike, dip, rake] ([300, 34, -143] corresponds to the composite focal mechanism of the superficial events of Batsi et al., 2018; the other orientations are faults observed on the high resolution seismic profiles), and two different Skempton coefficients B of 0.1 (a) and 0.6 (b). We use a ramp source function with different rise times $\left(\tau_{R}=0.3,0.5\right.$ and $\left.1 \mathrm{~s}\right)$. The first and second rows correspond to the Coulomb stress variations for the isotropic model and the pore pressure changes calculated using equation 2 , respectively. 
some of the parameters given in section 3.3) $0.35 \mathrm{~m} / \mathrm{s}$ for a hydraulic opening of $100 \mu \mathrm{m}$, and $3.5 \mathrm{~mm} / \mathrm{s}$ for a hydraulic opening of $10 \mu \mathrm{m}$. Now considering that the newly formed fracture in which the gas is migrating terminates upward, the early stages of overpressure development at the fracture tip (assuming it is stationary) can be approximated from the solution of the diffusion equation with an initially uniform pressure gradient $(d P / d z)_{t_{0}}$ and an imposed no flow upper boundary (eq. 2.9.8 in Carslaw and Jaeger, 1959)

$$
P(t)-P\left(t_{0}\right)=2(d P / d z)_{t_{0}} \sqrt{\frac{D t}{\pi}},
$$

where $D$ is the pressure diffusion coefficient in the fracture. Under the in-situ conditions at the level of the aftershock cluster (around $30 \mathrm{MPa}$ and $60^{\circ} \mathrm{C}$ ), methane does not deviate strongly from a perfect gas ( $\mathrm{Z}$ factor of about 0.95) [Barth, 2005] and its isothermal compressibility may thus be approximated as 1 over the pressure. Hence, methane gas compressibility is of the order of 3.10-8 $\mathrm{Pa}^{-1}$ while that of water is of the order of 4.5.10 ${ }^{-10} \mathrm{~Pa}^{-1}$. The fluid storage in the fracture contains then a $1 / P$ term corresponding to the compressibility of the gas, and a $b / K_{n}$ term arising from fracture compliance, hence

$$
D=\frac{b^{2}}{12 \eta\left(\frac{1}{P}+\frac{b}{K_{n}}\right)} .
$$

We assume a normal stiffness $K_{n}$ for fractures and consider a probable range of $10^{1} 0$ to $10^{1} 1 \mathrm{~Pa} / \mathrm{m}$ based on laboratory experiments on shale samples [Ye et al., 2016]. We may then consider example cases of a relatively thin and compliant fracture ( $b$ of $10 \mu \mathrm{m}$ and $K_{n}$ of $\left.10^{1} 0 \mathrm{~Pa} / \mathrm{m}\right)$, implying a diffusivity of $0.04 \mathrm{~m}^{2} / \mathrm{s}$, and a relatively thick and rigid fracture ( $b$ of $100 \mu \mathrm{m}$ and $K_{n}$ of $10^{1} 1 \mathrm{~Pa} / \mathrm{m}$ ), implying a diffusivity of 300 $\mathrm{m}^{2} / \mathrm{s}$. The pressure rise after 30 seconds is slightly more that $10 \mathrm{kPa}$ in the first case and theoretically reaches 1 $\mathrm{MPa}$ in the second case (Figure 8). While this order-ofmagnitude calculation remains largely unconstrained, it shows that fluid migration induced by transient opening of fractures during or immediately after an earthquake could have effects comparable to, and possibly in some cases, much larger than poroelastic effects. Moreover, the square-root-of-time-dependency in eq. $7 \mathrm{im}$ plies that a significant pressure increase may be obtained early in the process, possibly while the seismic waves are still propagating in the medium. If dynamic effects during earthquakes could result in the transient opening of fractures by several tens of micrometers, or to fracture unclogging, the pressure variations potentially caused by gas migration in the fault zone could be sufficiently large to lead to their instability. In the case when the formation is initially overpressured, rather than at hydrostatic equilibrium, the possibility of triggering an instability by similar processes appears even more likely.

\section{Discussion}

Match filter techniques lead to the detection of a larger number of events that are not detected by classical detection schemes such as the ratio of short term average to long term average. For this study, the match filter approach results in a 2 -fold increase in events relocated. In order to improve the event detection in the SoM, a denser seismic network closer to the clusters would be required. The use of differential times derived from high-precision cross-correlation allows for a direct and semi-automatic use of double-difference relative locations with old and newly detected events. In our case, most of the child events are located within the shallow clusters at depths less than $5 \mathrm{~km}$. Location artifacts should be limited in our case since the use of different velocity models lead to similar results (3D velocity model of Géli et al., 2018 and 1-D velocity model of Tary et al., 2011). The position of the shallowest clusters especially, is a robust feature of these locations. More complex schemes such as subspace detection could be employed to further improve the detection process [e.g., Barrett and Beroza, 2014].

Taking into account the spatio-temporal distribution of the events, both static and dynamic stresses are potential triggering candidates. The computed Coulomb stress changes can only trigger seismicity for those faults that are close enough to failure. The presence of gas in the shallow sedimentary layers is attested by high-resolution seismic data [Thomas et al., 2012]. The presence of gas can also be inferred at depths of several kilometers from the geochemical signature of the seeping hydrocarbons, which point to a thermogenic source within Eocene-Oligocene Thrace basin sediments [Bourry et al., 2009; Ruffine et al., 2019], and considering the regional heat flow [Géli et al., 2018]. It can also be noted that the P-wave velocity beneath the Western High is anomalously low $(<4.2 \mathrm{~km} / \mathrm{s})$ down to a depth of 5-6 km below sea-level comparable to that of the adjacent syntectonic sedimentary basin [Bayrakci et al., 2013]. This may in part be due to the generation of gas in the lower part of the sedimentary pile, which comprises the Thrace basin formations. 
b)

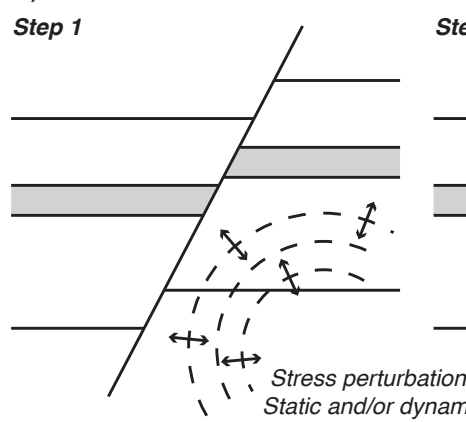

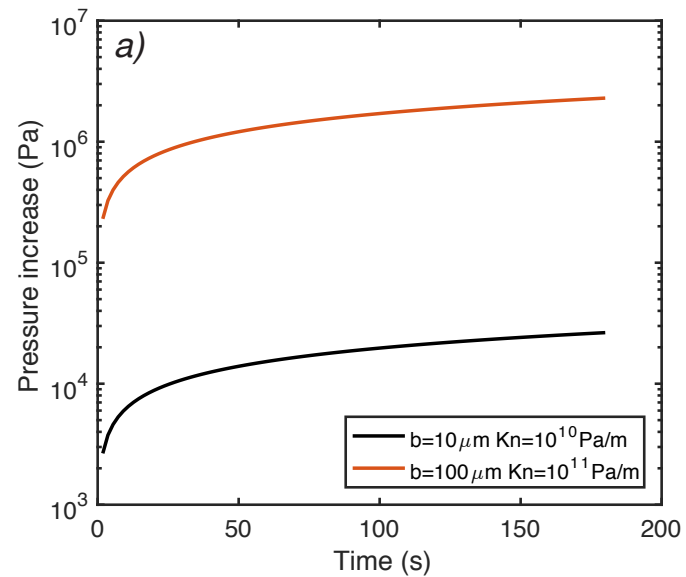

Step 2

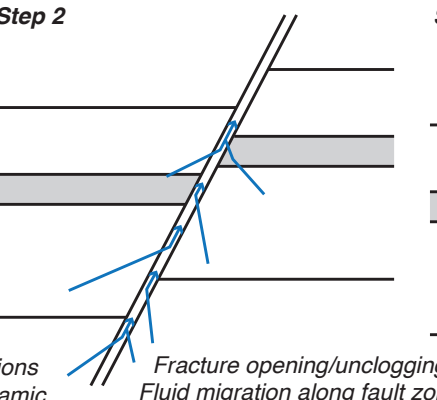

Step 3

Figure 8: a) Pressure increase due to permeability enhancement and gas migration initiated at $\mathrm{t}=0$. $\mathrm{b}$ ) Conceptual model for the triggering of fault instability and reactivation by stress perturbations. 
The correlation between the locations of the shallow seismic clusters and gas reservoirs strongly points towards the gas being a triggering factor. However, the gas compressibility will act as a buffer for any stress transfer effect on the faults because an increase in pore pressure will lead to an increase in gas compressibility which will decrease the pore pressure, and viceversa for a decrease in pore pressure. This is observable in Figure 7 when comparing pore pressure variations $(\Delta \mathrm{p})$ calculated using different Skempton coefficients. In addition, if no permanent deformation occurs during Coulomb stress loading, stress transfer wont lead to long-lasting effects. The sequence lasting for $\sim 6$ days, other effects, or a combination of effects, after the stress perturbation must be invoked to explain the triggering of the shallow clusters. The sequence duration due to Coulomb stress transfer could increase if some inter-event stress triggering occurs. Hence, we cannot rule out that some of the events of the cluster might also have been triggered locally by previous events within the cluster.

If gas is influencing seismicity, some other mechanisms must be considered. Fluid migration along faults at $\mathrm{km}$ scale has been proposed to explain migration of seismic activity with time over days to months [e.g., Miller et al., 2004]. However, there is no evidence in our data set that the spatial distribution of seismicity follows a specific pattern with time (Figure 5b). The first aftershocks are triggered only minutes after the main shock and their distribution in time follows Omori's law. If pore fluids are involved in the early shallow aftershock generation, it must be through a relatively fast process involving local fluid sources. This leads us to hypothesize that fault permeability enhancement caused by the earthquake could enable local scale fluid migrations and variations in pore pressure. Moreover, it has been shown that geopressured fluid-filled cracks become unstable and migrate upward when they reach a critical size, which depends on the fluid physical properties and the mechanical properties of the formation [Nunn, 1996]. For methane, the critical size of the cracks is only a few meters and the velocity of ascent is estimated to range between 0.01 to $1 \mathrm{~m} / \mathrm{s}$ depending on the fracture toughness of the formation, which appears as the main unknown parameter [Nunn and Meulbroek, 2002]. Despite some uncertainty on the response of gas-filled fractures to earthquake shaking, a local and transient increase in permeability in gas bearing sedimentary rocks could then initiate migration by collecting gas into a fracture, or a connected network of fractures, until it reaches a critical size leading to significant overpressures and trigger fault reactivation and seismic events (Figure 8b). A similar mechanism generating large overpressures involving stress perturbation followed by fluid migration could also apply to other contexts where fluids are present such as hydrothermal systems.

\section{Conclusion}

The use of match filter technique decreased the detection magnitude of the marine seismological network improving the detection and confirming the existence of shallow clusters of seismicity that followed the $\mathrm{M}_{w} 5$ earthquake on July 25, 2011. Computations of Coulomb stress-transfer yield dynamic stresses variations of at most about $\pm 40 \mathrm{kPa}$ during the first $30 \mathrm{~s}$ after the mainshock and static stress variations of less than $5 \mathrm{kPa}$, even though these values depend strongly on the receiver faults considered. The triggering of this sequence being associated with relatively small stress variations likely indicates that the faults at this location in the SoM are in a state close to failure. The sequence duration of the shallow clusters suggests that triggering processes other than Coulomb stress variations have likely played a key role. The Western High is an area in the SoM characterized by intense fluid manifestations, the most striking feature being the presence of a mud volcano to the side of the NAF. In the present case, a feedback between fluids and seismicity might be at play. The large amount of gas present in the area might have altered the dynamic response of the faults, promoting earthquake triggering.

\section{Acknowledgments}

Data were acquired part of the ESONET Network of Excellence (contract N 036851). Jean-François Rolin and Roland Person, coordinators of ESONET, are particularly acknowledged. We also thank the Turkish Navy and the Turkish Hydrographic Service (SHOD) for their help with the cruises, especially Captain Erhan Gezgin; and the personnel of the French Embassy in Ankara, particularly Mrs Bonnafous-Boucher; to $\mathrm{CNR}$ and to Ifremer for funding operations at sea of R/V Le Suroit, R/V Pourquoi pas? and R/V Urania, respectively; to the Institute of Marine Science and Technology of the University of Izmir for support with R/V Piri Reis; to Pascal Pelleau, Mickal Roudaut and Ronan Apprioual for their technical support; to professor Oguz Özel, for his support for using R/V Yunuz of Istanbul University. We also thank two anonymous reviewers for their comments which improved the quality of this study. Jean-Baptiste Tary 
was supported by the FAPA project (PR.3.2016.3047; Universidad de los Andes). Anthony Lomax was funded by the bilateral ANR/TÜBITAK collaborative research project MAREGAMI (ANR-16-CE03-001002 and Tübitak Project 116Y371). The Generic Mapping Tools (GMT) was used for figures 1 and 6. All data used in this paper are available on request to the authors.

\section{References}

Aksoy, E.M., Meghraoui, M., Vallée, M., Cakir, Z., 2009. Rupture characteristics of the 1912 Mürefte (Ganos) earthquake segment of the North Anatolian fault (Western Turkey), Eos Trans. AGU 90, 52, Fall Meet. Suppl., abstract no. T13C-1884.

Barka, A., Akyüz, H.S., Altunel, E., Sunal, G., Çakir, Z., Dikbas, A., Yerli, B., Armijo, R., Meyer, B., de Chabalier, J.B., Rockwell, T., Dolan, J.R., Hartleb, R., Dawson, T., Christofferson, S., Tucker, A., Fumal, T., Langridge, R., Stenner, H., Lettis, W., Bachhuber, J., Page, W., 2002. The Surface Rupture and Slip Distribution of the 17 August 1999 zmit Earthquake (M 7.4), North Anatolian Fault, Bulletin of the Seismological Society of America 92(1), 43-60; doi: 10.1785/0120000841.

Barrett, S.A., Beroza, G.C., 2014. An Empirical Approach to Subspace Detection. Seismological Research Letters 85(3), 594-600. doi:10.1785/0220130152.

Barth, G. A., 2005. Methane Gas Volume Expansion Ratios and Ideal Gas Deviation Factors for the Deep-Water Bering Sea Basins, U. S. Geological Survey, Open-File Report 2005-1451.

Batsi, E., Lomax, A., Tary, J.B., Klingelhoefer, F., Riboulot, V., Murphy, S., Monna, S., Özel, N M., Kalafat, D., Saritas, H., Cifçi, G., Çagatay, N., Gasperini, L., Géli, L., 2018. An alternative view of the microseismicity along the Western Main Marmara Fault, based on a high-resolution study, Bulletin of the Seismological Society of America 108(5A), 2650-2674.

Bayrakci, G., Laigle, M., Bécel, A., Hirn, A., Taymaz, T., Yolsal-Çevikbilen, S., SEISMARMARA team, 2013. 3-D sediment-basement tomography of the Northern Marmara trough by a dense OBS network at the nodes of a grid of controlled source profiles along the North Anatolian fault, Geophys. J. Int. 194(3), 1335-1357. doi: 10.1093/gji/ggt211.

Bécel, 2006, Structure sismique de la Faille Nord Anatolienne en Mer de Marmara, Ph. D. Thesis, Institut de physique du globe de Paris (IPGP), Paris, France.
Bohnhoff, M., Bulut, F., Dresen, G., Malin, P.E., Eken, T., Aktar, M., 2013. An earthquake gap south of Istanbul, Nat. Commun., 4:1999. doi:10.1038/ncomms2999.

Bouchon, M., 1981. A simple method to calculate Greens functions for elastic layered media, Bull. seism. Soc. Am. 71(4), 959-971.

Bourry, C., Chazallon, B., Charlou, J.L., Donval, J.P., Ruffine, L., Henry, P., Gli, L., agatay, N., nan, S., Moreau, M., 2009. Free gas and gas hydrates from the Sea of Marmara, Turkey Chemical and structural characterization, Chem. Geol. 264, 197206.

Brown, J. R., Beroza, G.C., Shelly, D.R., 2008. An autocorrelation method to detect low frequency earthquakes within tremor, Geophys. Res. Lett., 35, L16305. doi:10.1029/2008GL034560.

Burnard, P., Bourlange, S., Henry, P., Géli, L., Tryon. M.D., Natalin, B., Sengör, A.M.C., Özeren, M.S., Çagatay, M.N., 2012. Constraints on fluid origins and migration velocities along the Marmara Main Fault (Sea of Marmara, Turkey) using helium isotopes, Earth Planet. Sci. Lett. 341-344, 68-78.

Carslaw, H. S., Jaeger, J. C., 1959. Conduction of heat in solids (2nd ed.), Oxford University Press, London.

Castagna, J.P., Batzle, M.L., Eastwood, R.L., 1985. Relationships between compressionalwave and shearwave velocities in clastic silicate rocks, Geophysics 50(4), 571-581. doi:10.1190/1.1441933.

Cocco, M., Rice, J.R., 2002. Pore pressure and poroelasticity effects in Coulomb stress analysis of earthquake interactions, J. Geophys. Res. 107(B2). doi:10.1029/2000JB000138.

Cotton, F., Coutant, O., 1997. Dynamic stress variations due to shear faults in a plane-layered medium, Geophys. J. Int. 128, 676-688.

De Landro, G., Amoroso, O., Stabile, T.A., Martullo, E., Lomax, A., Zollo, A., 2015. High precision Differential Earthquake Location in 3D models: Evidence for a rheological barrier controlling the microseismicity at the Irpinia fault zone in southern Apennines, Geophys. J. Int. 203(3), 1821-1831. doi: 10.1093/gji/ggv397.

Dupré, S., Scalabrin, C., Grall, C., Augustin, J.M., Henry, P., Şengör, A.M.C., Görür, N., Çagatay, M.N., Géli, L., 2015. Tectonic and sedimentary controls on widespread gas emissions in the Sea of Marmara: Results from systematic, shipborne multibeam 
echo sounder water column imaging, J. Geophys. Res. Solid Earth 120, $2891291 .$, doi:10.1002/2014JB011617.

Ergintav, S., Reilinger, R.E., Çakmak, R., Floyd, M., Cakir, Z., Dogan, U., King, R.W., McClusky, S., Özener, H., 2014. Istanbul's earthquake hot spots: Geodetic constraints on strain accumulation along faults in the Marmara seismic gap, Geophys. Res. Lett. 41, 57835788, doi:10.1002/2014GL060985.

Erickson, S.N., Jarrard, R.D., 1998. Velocityporosity relationships for water-saturated siliciclastic sediments, J. Geophys. Res., 103(B12), 30385-30406. doi:10.1029/98JB02128.

Freed, A. M., 2005, Earthquake triggering by static, dynamic, and postseismic stress transfer, Annual Review of Earth and Planetary Sciences, 33(1), 335-367. doi: 10.1146/annurev.earth.33.092203.122505.

Géli, L., Henry, P., Zitter, T., Dupré, S., Tryon, M., Çagatay, M.N., Mercier de Lépinay, B., Le Pichon, X., Şengör, A.M.C., Görür, N., et al., (2008). Gas emissions and active tectonics within the submerged section of the North Anatolian Fault zone in the Sea of Marmara. Earth Planet. Sci. Lett., 274(1-2), 34-39. doi: 10.1016/j.epsl.2008.06.047.

Géli, L., Henry, P., Grall C., Tary, J.B., Lomax, A., Batsi E., Cros, E., Gürbüz C., Isik, S. E., Sengör A. M. C., et al., (2018). Gas related seismicity within the Istanbul seismic gap, Scientific Reports, 8, 6819. doi: 10.1038/s41598-018-23536-7.

Grall, C., Henry, P., Thomas, Y., Westbrook, G.K., Çagatay, M.N., Marsset, B., Saritas, H., Çifçi, G., Géli, L., 2013. Slip rate estimation along the western segment of the Main Marmara Fault over the last 405-490 ka by correlating mass transport deposits, Tectonics, 32, 15871601, doi:10.1002/2012TC003255.

Kenneth, B.L.N., Kerry, N.J., 1979. Seismic waves in a stratified half space, Geophys. J. R., astr. Soc. 57, $557-583$.

Klein, E., Duputel, Z., Masson, F., Yavasoglu, H., Agram, P., 2017. Aseismic slip and seismogenic coupling in the Marmara Sea: What can we learn from onland Geodesy?, Geophys. Res. Lett. 44, 3100-3108. doi:10.1002/2017GL072777.

Konca, A.O., Leprince, S., Avouac, J.-P., Helmberger, D.V., 2010. Rupture Process of the $1999 \mathrm{Mw}$ 7.1 Duzce Earthquake from Joint Analysis of SPOT, GPS, InSAR, Strong-Motion, and Teleseismic Data: A Supershear Rupture with Variable Rupture Veloc- ity, Bull. seism. Soc. Am. 100 (1), 267288. doi: 10.1785/0120090072.

Kuşçu, I., Okamura, M., Matsuoka, H., Gökaşan, E., Awata, Y., Tur, H., Şimşek, Keer, M., 2005. Seafloor gas seeps and sediment failures triggered by the August 17, 1999 earthquake in the Eastern part of the Gulf of Izmit, Sea of Marmara, NW Turkey, Mar. Geol. 215, 193-214. doi: 10.1016/j.margeo.2004.12.002.

Lin, J., Stein, R.S., 2004. Stress triggering in thrust and subduction earthquakes and stress interaction between the southern San Andreas and nearby thrust and strike-slip faults, J. Geophys. Res. 109, B02303. doi:10.1029/2003JB002607.

Lomax, A., Michelini, A., Curtis, A., 2009. Earthquake Location, Direct, Global-Search Methods, in: Complexity In Encyclopedia of Complexity and System Science, Part 5, Springer, New York, pp. 2449-2473, doi:10.1007/978-0-387-30440-3.

Madariaga, R., 1976. Dynamics of an expanding circular fault, Bull. Seism. Soc. Am. 66 (3), 639-666.

Manga, M., Wang, C.-Y., 2007. Earthquake hydrology, in: G. Schubert (ed.), Treatise on Geophysics, 4, Elsevier, Amsterdam, pp. 293-320. doi:10.1016/B978044452748-6.00074-2.

Makhnenko, R. Y., Labuz, J. F., 2013. Saturation of Porous Rock and Measurement of the B Coefficient. American Rock Mechanics Association, ARMA-2013468.

Miller, S.A., Collettini, C., Chiaraluce, L., Cocco, M., Barchi, M., Kaus, B.J.P., 2004. Aftershocks driven by a high-pressure $\mathrm{CO} 2$ source at depth, Nature 427 , 724-727. doi: 10.1038/nature02251.

Nunn, J. A., 1996. Buoyancy-driven propagation of isolated fluid-filled fractures: implications for the fluid transport in Gulf of Mexico geopressured sediments, J. Geophys. Res. 101, 2963-2970.

Nunn, J. A., Meulbroek, P., 2002. KilometerScale Upward Migration of Hydrocarbons in Geopressured Sediments by Buoyancy-Driven Propagation of Methane-Filled Fractures. AAPG Bulletin 86(5), 907918.

Remitti, F., Smith, S. A. F., Mittempergher, S., Gualtieri, A. F., Di Toro, G., 2015. Frictional properties of fault zone gouges from the J-FAST drilling project (Mw 9.0 2011 Tohoku-Oki earthquake), Geophys. Res. Lett. 42, 2691-2699. doi:10.1002/ 2015GL063507. 
Rice, J.R., Cleary, M.P., 1976. Some basic stress diffusion solutions for fluid-saturated elastic porous media with compressible constituents, Reviews of Geophysics and Space Physics, 14(2), 227-241. doi:10.1029/RG014i002p00227.

Roeloffs, E.A., 1998. Persistent water level changes in a well near Parkfield, California, due to local and distant earthquakes, J. Geophys. Res. 103, 869-889.

Ruffine, L., Donval, J.-P., Croguennec, C., Burnard, P., Lu, H., Germain, Y., Legoix, L., Bignon, L., aatay, M.N., Marty, B., Madre, D., Pitel-Roudaut, M., Henry, P., Gli, L., 2019. Multiple gas reservoirs are responsible for the gas emissions along the Marmara fault network, Deep Sea Res. II Topical Studies in Oceanography 153, 48-60. doi: 10.1016/j.dsr2.2017.11.011.

Sakic, P., Piété, H., Ballu, V., Royer, J.-Y., Kopp, H., Lange, D., Petersen, F., Özeren, M.S., Ergintav, S., Géli, L., Henry, P., Deschamps, A., 2016. No significant steady state surface creep along the North Anatolian Fault offshore Istanbul: Results of 6 months of seafloor acoustic ranging, Geophys. Res. Lett. 43, 6817-6825. doi:10.1002/2016GL069600.

Schmittbuhl, J., Karabulut, H., Lengliné, O., Bouchon, M., 2016a. Long-lasting seismic repeaters in the Central Basin of the Main Marmara Fault, Geophys. Res. Lett., 43, 9527 9534, doi: 10.1002/2016GL070505.

Schmittbuhl, J., Karabulut, H., Lengliné, O., Bouchon, M., 2016b. Seismicity distribution and locking depth along the Main Marmara Fault, Turkey, Geochem. Geophys. Geosyst., 17, 954-965, doi: 10.1002/2015GC006120.

Şengör, A. M. C., Grall, C., Imren, C., Le Pichon, X., Görör, N., Henry, P., Karabulut, H., Siyako, M., 2014. The geometry of the North Anatolian transform fault in the Sea of Marmara and its temporal evolution: implications for the development of intracontinental transform faults, Can. J. Earth Sci., 51 (3), 222-242. doi:10.1139/cjes-2013-0160.

Stein, R. S., Barka, A.A., Dieterich, J.H., 1997. Progressive failure on the North Anatolian fault since 1939 by earthquake stress triggering, Geophys. J. Int., 128, 594-604. doi:10.1111/j.1365-246X.1997.tb05321.x

Tary, J.B., Apoloner, M.-T., Bokelmann, G., 2015. Earthquake interactions during the 2013 Ebreichsdorf aftershock sequence, Austrian Journal of Earth Sciences 108/2, 209-218. doi:10.17738/ajes.2015.0022.
Tary, J.B., Géli, L., Henry, H., Natalin, B., Gasperini, B., Çomoglu, M., Çagatay, N., Bardainne, T., 2011. Sea bottom observations from the western escarpment of the Sea of Marmara, Bull. seism. Soc. Am. 101, 775791. doi:10.1785/0120100014.

Thomas, Y., Marsset, B., Westbrook, G., Grall, C., Géli, L., Henry, P., Çifçi G., Rochat, A., Saritas, H., 2012. Contribution of high-resolution 3D seismic near-seafloor imaging to reservoir-scale studies: application to the active North Anatolian Fault, Sea of Marmara, Near Surface Geophysics, 10(4), 291-301. doi:10.3997/1873-0604.2012019.

Toda, S., Stein, R.S., Richards-Dinger, K., Bozkurt, S.B., 2005. Forecasting the evolution of seismicity in southern California: Animations built on earthquake stress transfer, J. Geophys. Res. 110, B05S16. doi:10.1029/2004JB003415.

Tryon, M. D., Henry, P., Çagatay, M.N., Zitter, T. A. C., Géli, L., Gasperini, L., Burnard, P., Bourlange, S., Grall, C., 2010. Pore fluid chemistry of the North Anatolian Fault zone in the Sea of Marmara: a diversity of sources and processes, Geochem. Geophys. Geosyst. 11, 1-22. doi:10.1029/2010GC003177.

Wells, D. L., Coppersmith, K. J., 1994. New empirical relationships among magnitude, rupture length, rupture width, rupture area, and surface displacement, Bull. Seismol. Soc. Am. 84(4), 974-1002.

Zitter, T. A. C., Henry, P., Aloisi, G., Delaygue, G., Çagatay, M.N., Mercier de Lépinay, B., Al-Samir, M., Fornacciari, F., Tesmer, M., Pekdeger, A., Wallmann, K., Lericolais, G., 2008. Cold seeps along the main Marmara fault in the Sea of Marmara (Turkey), Deep Sea Res. 55, 552570. doi: 10.1016/j.dsr.2008.01.002.

Ye, Z., Ghassemi, A., Riley, S., 2016. Fracture Properties Characterization of Shale Rocks, Unconventional Resources Technology Conference, San Antonio (TX), USA. 